\title{
P04.62. Systematic review of clinical studies of whole practice naturopathic medicine
}

\author{
C Calabrese $^{1 *}$, E Oberg $^{2}$, R Bradley ${ }^{2}$, D Seely ${ }^{3}$, K Cooley $^{3}$, J Goldenberg ${ }^{2}$ \\ From International Research Congress on Integrative Medicine and Health 2012 \\ Portland, Oregon, USA. 15-18 May 2012
}

\begin{abstract}
Purpose
Individualized combinations of therapeutic modalities and remedies are generally the rule in naturopathic practice with selection determined by the system's principles and guidelines. With the wide variation in realworld use, evaluating the whole practice best assesses overall benefits and risks. Naturopathic doctors in Canada and the US in licensed jurisdictions receive accredited training to a common standard resulting in practice that may be distinct from that in unregulated jurisdictions or in other countries. We seek to represent the landscape of clinical studies in licensed North American naturopathic medicine to identify gaps in knowledge and generate hypotheses for future study.
\end{abstract}

\section{Methods}

Through a systematic review, we accessed clinical studies in acute and chronic diseases in which licensed naturopathic clinicians were allowed access to therapeutic and diagnostic tools within their scope of practice or to well-described models of current whole practice. Databases searched include AMED, EMBASE, MEDLINE, PREMEDLINE and the Cochrane Library. In addition, content experts were consulted and the lay literature hand-searched to identify additional relevant studies. The review was performed and reported according to PRISMA guidelines for systematic reviews and describes for each study participants, interventions, comparisons, outcomes, and study design.

\section{Results}

We have so far identified 12 studies fitting inclusion criteria with a variety of designs in anxiety, tendinitis, temporomandibular joint disorder, low back pain, general pain, hypertension, multiple sclerosis, menopausal

${ }^{1}$ Naturopathic Physicians Research Institute, Portland, USA

Full list of author information is available at the end of the article symptoms, cardiovascular risk and type 2 diabetes. Six were randomized trials including 2 with cost components, one a comparative prospective observational study, one a prospective single group observation, and four were retrospective. All showed some evidence of effectiveness though most had methodological weaknesses. No studies in acute disease meeting criteria were found.

\section{Conclusion}

The review provides evidence of effectiveness and cost savings that merit further investigation of naturopathic care for chronic disease.

\section{Author details}

${ }^{1}$ Naturopathic Physicians Research Institute, Portland, USA. ${ }^{2}$ Bastyr University, Kenmore, USA. ${ }^{3}$ Canadian College of Naturopathic Medicine, Toronto,

Canada.

Published: 12 June 2012

doi:10.1186/1472-6882-12-S1-P332

Cite this article as: Calabrese et al:: P04.62. Systematic review of clinical studies of whole practice naturopathic medicine. BMC Complementary and Alternative Medicine 2012 12(Suppl 1):P332.

Submit your next manuscript to BioMed Central and take full advantage of:

- Convenient online submission

- Thorough peer review

- No space constraints or color figure charges

- Immediate publication on acceptance

- Inclusion in PubMed, CAS, Scopus and Google Scholar

- Research which is freely available for redistribution 